\title{
Case Study Of Postgraduate Student Dropout Rate At South African Universities
}

\author{
A. Styger, North-West University, South Africa \\ G. W. van Vuuren, North-West University, South Africa \\ A. Heymans, North-West University, South Africa
}

\begin{abstract}
Public funding for higher education in South Africa is a significant investment. Large amounts of funds are invested in students and there is a national shortage of high quality students in scarce skills - in particular, students with a postgraduate qualification. Students tend to take longer to complete their studies which contributes to the workload of academic staff. Dropouts are affecting the deliverance of these students in a negative way and priceless research from these students is never delivered and published. Not only are fewer students and research being delivered, but large amounts of funding and human capital are wasted on educating students who will never complete their studies. Postgraduate studies have a potential greater loss, and a beta distribution on the dropout can predict the expected and unexpected loss for these students. The latter is an area for concern and needs to be assessed and addressed as soon as possible.
\end{abstract}

Keywords: Student Dropout Rate; Student Retention; Financial Loss; Education Funding

\section{INTRODUCTION}

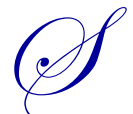

outh Africa has one of the lowest global graduation rates for higher education - $15 \%$ - and this, coupled with the fact that the labour market has a shortage of scarce skills (Letseke \& Maile, 2008:1), should raise concern among university management. The cost of postgraduate student supervision represents a considerable investment for both the institution and the government and if only $15 \%$ of enrolled students graduate, both parties should be concerned about postgraduate graduation. The reputations of higher education institutions hinge on postgraduate success, defined by students completing their studies in the minimum time (Kritzinger \& Loock, 2012:1).

Student dropout rate is a national phenomenon (Kritzinger \& Loock, 2012:11) and a number of studies (for example, Iputo et al., 2005; Lubben et al., 2010; Pretorius et al., 2010) have been conducted on undergraduate students but very few (for example, Kritzinger and Loock, 2012; ASSAF, 2010) on postgraduate students. Dropout rates in 2010 ranged from 30 to $67 \%$ for master's degrees and 50 to $68 \%$ for doctoral degrees for some academic colleges of the biggest university in South Africa - statistics that require urgent investigation (Kritzinger \& Loock, 2012:12). In terms of subsidised research output units for an institution in South Africa, doctoral graduates provide three units of research each (Ministry of Higher Education and Training, 2012:7) and if students drop out, these are completely lost, along with substantial funding in the form of government subsidies and vital research. Crest (2009) asserted that the national strategy is to increase postgraduate qualifications (through education) to accelerate human capital development (Kritzinger \& Loock, 2012:2). For South African universities to remain competitive globally, this goal is important. Doctoral students are taking longer to complete their studies - the average time for completion of a doctoral degree in 2007 was 4.8 years, up from 4.6 in 2000 (ASSAF, 2010:72). Factors that influence student retention and throughput internationally are mostly attributed to student under-preparedness, including the challenges in the school system (Pretorius et al., 2010:132). This indicates that students are not prepared for the academic challenges that lie ahead in post-school studies.

King (2004) found that South Africa can be compared to countries such as Russia, Poland and Brazil in terms of its citation intensity (ASSAF, 2010:21). The same study found clear correlations between the citation intensity of a nation and its economic wealth. In the ten-year plan of the Department of Science and Technology 
(DST), the goal is set to place South Africa among the ranks of wealthier countries by increasing knowledge output significantly (Department: Science and Technology, 2007:4). This means that research master's and doctoral outputs must also increase in both quality and quantity which, however, requires a number of crucial inputs, including postgraduate supervisors, infrastructure and, of course, students. If students continue to drop out at the rate as in the study of ASSAF (2010), large amounts of funds invested in these students are lost, not to mention human capital wasted.

In 2010, South Africa delivered approximately 23 to 27 doctoral students per million residents in the population per annum (ASSAF, 2010:21) and the target set by the DST is to deliver 6,000 PhDs in science, engineering and technology (SET) alone by 2018 - five times the current number (Department: Science and Technology, 2007:28). To achieve this goal, higher education institutions cannot continue in their current ways and increasing PhD student intake will only partially solve the problem. To enrol more students, more supervisors are required - supervisors that are scarce. Qualified academic staff and, in particular, doctoral supervisors are in short supply in South Africa (ASSAF, 2010:65) and current staff are ageing. To qualify as a supervisor for a PhD student, a $\mathrm{PhD}$ degree or equivalent is the minimum requirement. In 2011, nearly 13,000 doctoral and 49,000 master's students enrolled for higher education at public institutions in South Africa. During the same year, there were close to 17,000 permanent academic staff members, resulting in an average of 0.8 doctoral and 2.9 master's students per permanent academic staff member (Department of Higher Education and Training, 2013:5).

Apart from the fact that the student dropout rate is high, students tend to take longer to complete their studies. In 2005, 37\% of master's students and 59\% of doctoral students in South Arica were on-going students (i.e., those who had begun their studies in previous years and were merely continuing their postgraduate degrees), while the graduation rate stayed the same (Crest, 2009). This contributes to the workload of academic staff. The ratio of deliverables to input defines the productivity of any system (Crest, 2009:7). Since 2000, the South African higher education system has delivered more postgraduate students, but many more are needed. Master's graduates increased from nearly 5,800 in 2000 to nearly 9,700 in 2011 - an increase of $67 \%$. During the same period, doctoral graduates increased by $91 \%$ - from 822 to 1,576 . Although the number of postgraduates increased, many more are needed to meet the targets set by the DST in 2007.

If institutions are to meet the targets set by the DST for 2018 research and doctoral output, more must be done to improve the success rate of current students, as well as keeping dropout rates to a minimum. Considering the higher education sector's changes over the past 15 to 20 years, including the merging of some universities and technikons, the stage is set for South Africa to rise to the challenge and deliver quality students, especially in the areas of scarce skills (Crest, 2009:1). This paper aims to provide insight into the potential financial loss for subsidy income for postgraduate students for the North-West University for the coming years, based on the dropout rates in recent years through a case study.

\section{LITERATURE STUDY}

Student retention is not only a problem for South Africa (Kritzinger \& Loock, 2012:11) but has also become an area of concern for higher education institutions in the United States of America (Lau, 2003:126). Students returning for an extra year to complete their studies results in financial losses for the institution and also damages the image of the institution among its peers. Nash (1996) observed the same problem among academic institutions in the UK and student retention is an important factor for universities in the UK in the recruitment of external funding (Lau, 2003:126). It is clear that student retention is a global area of concern that requires urgent attention.

Studies in the USA have shown that institutions with a high retention rate for first-year students tend to have a high graduation rate (Lau, 2003:126). An effective strategy to retain students could prove to be a wise and meaningful investment. The reasons for student dropout rates differ from institution to institution, but research has shown that the majority of students tend to drop out early, usually during their first year of study (Lau, 2003:127). Terenzini et al. (1996) observed a number of reasons for students not returning to college in the USA, which include reasons beyond the control of the institution such as lack of finances, personal reasons, and ill-suited environments (Lau, 2003:127). 
In South Africa, the National Student Financial Aid Scheme (NSFAS) provides financial assistance to a large number of students and the Department of Higher Education and Training makes sure to address the needs of students in this way. R437mm was set aside for NSFAS in 2000 and by the year 2006, the amount grew by $112 \%$, to R926mm (De Villiers, 2009:4). For the 2012/13 financial year, more than R3.7bn was awarded toward financing the scheme with the amount increasing exponentially every year (Ministry of Higher Education and Training, 2012:2). The same increase applied to research outputs (R2.5bn for 2012/13) and since postgraduate students are mostly research output (Ministry of Higher Education and Training, 2012:7), a significant investment is being made into these students. Keeping students enrolled (retained) should be a key area of concern for university management to maximise their return on investment.

Tinto (1987) argued that student life or experience was the key factor in student retention (Lau, 2003:2). From the study, it was clear that students tend to stay in school when their academic and social needs meet their expectations. The opposite was also true - students who had less than ideal experiences lost interest in their studies, academic staff, and eventually the institution. It is clear that as long as students are happy, they return. Reyes (1997) found that support services, including academic and career advice to students, played a large role in the success of student retention at a number of institutions in the USA (Lau, 2003:3). Other support services included learning centres, first-year programmes, and academic talent programmes.

Initiatives for academic staff also played a role. Brace and Robert (1997) and Wise and Groom (1996) observed the use of multimedia technology during contact sessions with students and found that they provide an enriching environment toward students (Lau, 2003:6). With the right choice of technology, students can be visually stimulated and their ability to understand material increased. Absher and Gatlin (1997) argued that "learning should be treated as a dynamic, not static, process" (Lau, 2003:7). For this reason, they suggested that practical experiences are more important than theoretical knowledge in the education of students as those with more practical sessions showed better problem-solving and creativity skills. The most important factor in student retention is students themselves (Lau, 2003:9). They are responsible for their academic results and the motivation to remain academically active.

Cloete and Bunting (2000) expressed multiple concerns that the graduation rates were too low for South African universities (Letseka et al., 2009:1). Although the success rate for full-time equivalent (FTE) students is $84 \%$ (i.e., the number of modules passed as a percentage of modules enrolled), low graduation rates (ranging from 6 to $24 \%$ for South African institutions) provide reasons for concern on student dropout rate for the Department of Education (DoE) (Letseka et al., 2009:2). The graduation rate is calculated as the percentage of students who complete their studies in the minimum time for a specific qualification for the cohort that started the qualification. Seasonal factors, such as significant increases in student enrolment, would therefore lead to artificial decreases in graduation rates. For this reason, only cohort studies provide a clear view of student success. The DoE reported that $30 \%$ of the 120,000 students that enrolled in higher education in South African institutions in 2000 terminated their studies within their first year. During the second and third year of study, an additional 20\% terminated their studies, (Letseka et al., 2009:3) which means that 50\% of all new students will never make it to graduation, let alone in the minimum time.

Spady (1970:64) found that a theoretical model could not account for most factors that contribute to the student dropout rate (Pretorius et al., 2010:132). Most current model results are derived from higher education systems based in North America and Europe; very little research exists for African universities (Pretorius et al., 2010:132). A student's motivation contributes to student retention and throughput, which means that students determine their own success in some way and this motivation is a combination of political, social, economic and environmental needs (Pretorius et al., 2010:133). Prinsloo et al. (2009) argued that the awareness of student risk by students themselves will raise the success rate for an institution. This was confirmed by Pretorius et al. (2010) who found a positive relationship between awareness of student risk and student success.

A survey that details financial losses from student dropout rates may encourage institutions to examine student retention more closely (Koen, 2007:2). Rossouw (2001) found that around R1.3bn in public funding is lost per annum as a result of the student dropout rate (Koen, 2007:9). Institutions that are financially sound tend not to pay much attention to the student dropout rate and those that do pay attention do so firstly at the postgraduate level. 
The argument is that the return on investment for master's and doctoral students is much higher than those for undergraduate students. South African literature on student retention is mostly theoretical, but international studies provide more technical details (Koen, 2007:75). Student retention in South Africa lacks research and more effort is needed if the sector wishes to reach higher targets for graduation rates.

The student dropout rate for postgraduate students at North-West University (NWU) was observed from 2008 to 2012 to determine patterns in historical dropouts and to predict future dropouts. By constructing a model to calculate the maximum income from subsidy per curriculum, the predicted loss in income can be explored through a case study for one of the higher education institutions in South Africa.

\section{DATA AND METHODOLOGY}

To make accurate predictions for the student dropout rate and predict loss of income, two sets of data were used for the purpose of this study. Firstly, data on the student dropout rate were sourced from the Higher Education Management Information Systems (HEMIS system) of the North-West University (NWU). Management Information Systems (MIS) at the NWU track the student dropout rate based on the students' unique student numbers through cohort studies. The cohort for the dropout rate is defined for the faculty as the number of students registered within the faculty for the first time. The number of dropouts per qualification type per faculty is then expressed as a percentage of the cohort. A student is classified as a dropout for year $n$ if the following three requirements are satisfied:

1. The student was enrolled for a formal qualification at the institution in year $n-1$.

2. The student is not a possible graduate.

3. The student is not registered in year $n$.

To calculate dropout percentages, the number of dropouts is divided by the number of enrolments for the institution. Student numbers identify transfer students remaining from the cohort. The reason that data for the NWU were used in this case study is because the same data for other institutions are not openly available and, as an employee of the NWU working with HEMIS data, the author has access to these datasets. The results of the study are therefore applicable to NWU and not necessarily to other institutions, since the student dropout rate at other institutions may be defined in a different manner and data will almost certainly yield different results. Nevertheless, the same broad dropout rate statistics are assumed to apply to higher education institutions throughout South Africa.

Data from 2008 to 2012 were chosen to provide an overview of the cohort dropouts for the past five years. For the purpose of this study, the focus is only on the postgraduate dropouts, since the subsidy income from these students is much higher (in excess of R350,000 per master's student and R650 000 per PhD graduate) than for undergraduate students and therefore the potential loss is also higher per student. Throughout the study, the assumption was made that the amounts per subsidy grant remain the same for future years to determine potential income and losses. The amounts for 2012 were as shown in Table 1.

Table 1: Subsidy Amounts

\begin{tabular}{|c|c|}
\hline Unit & Subsidy \\
\hline Teaching Input Unit (TIU) & R10 877 \\
\hline Teaching Output Unit (TOU) & R19764 \\
\hline Research Output Unit (ROU) & R115052 \\
\hline
\end{tabular}

According to the Potchefstroom Campus Plan 2013-2015, the mission of the NWU's Potchefstroom Campus is to become research-directed where excellence in teaching-learning and research is mutually strengthened (North-West University, 2012). This indicates the importance of postgraduate education and the focus on research that comes from postgraduate students. Postgraduate study guidance also takes a great deal of time from academic staff, compared to undergraduate classes, and human capital is wasted on at-risk students.

At first glance of the data, it was assumed that a simple linear regression model fitted to the model would be sufficient for the student dropout rate and financial loss projections. In a further study of the data, it became clear, 
however, that the differences between qualification types and faculties made it more complex. Dropout percentages ranged, for example, from a minimum of $7.8 \%$ in one faculty to a high of $51.6 \%$ in another faculty in the same year for master's degrees alone. A more complex statistical analysis was required for these data to make more robust assessments.

\section{Beta Distribution Details}

Several distributions were fitted to the dropout rate data with the beta distribution providing the best fit in all cases using the maximum likelihood method.

The $\beta$ distribution is completely characterised by two parameters, $\alpha$ and $\beta$, which are easily obtained from the mean $(\mu)$ and standard deviation $(\sigma)$ of the dropout rate data. These four quantities are linked as follows:

$\alpha=\mu \cdot\left(\frac{\mu \cdot(1-\mu)}{\sigma^{2}}-1\right)$

$\beta=(1-\mu) \cdot\left(\frac{\mu \cdot(1-\mu)}{\sigma^{2}}-1\right)$

From the time series of dropout rates, $\mu$ and $\sigma$ are measured empirically. Then, using Equations 1 and 2 above, $\alpha$ and $\beta$ are estimated and the probability density function for a beta distribution is plotted using:

$$
\begin{aligned}
P(x) & =\int_{0}^{x} \frac{(1-t)^{\beta-1} \cdot t^{\alpha-1} d t}{B(\alpha, \beta)} \\
& =\frac{\Gamma(\alpha+\beta)}{\Gamma(\alpha) \cdot \Gamma(\beta)} \cdot \int_{0}^{x}(1-t)^{\beta-1} \cdot t^{\alpha-1} d t
\end{aligned}
$$

with $0 \leq x \leq 1, \alpha, \beta>0$, where $x$ is the distribution variable, and $\Gamma$ is the standard Gamma function evaluated at the relevant parameters. Using Equation 3, the dropout rate may be estimated at any desired confidence interval; therefore, at a confidence interval of $95 \%$, for example, the value of $x$, when $P(x)=99 \%$, may be easily determined.

Figure 1 shows the histogram of empirical master's degree dropout rates for the period spanning from 2008 to 2012. Applying Equations 1 through 3 to these data determines the probability density function for master's degree dropouts as plotted in Figure 2.

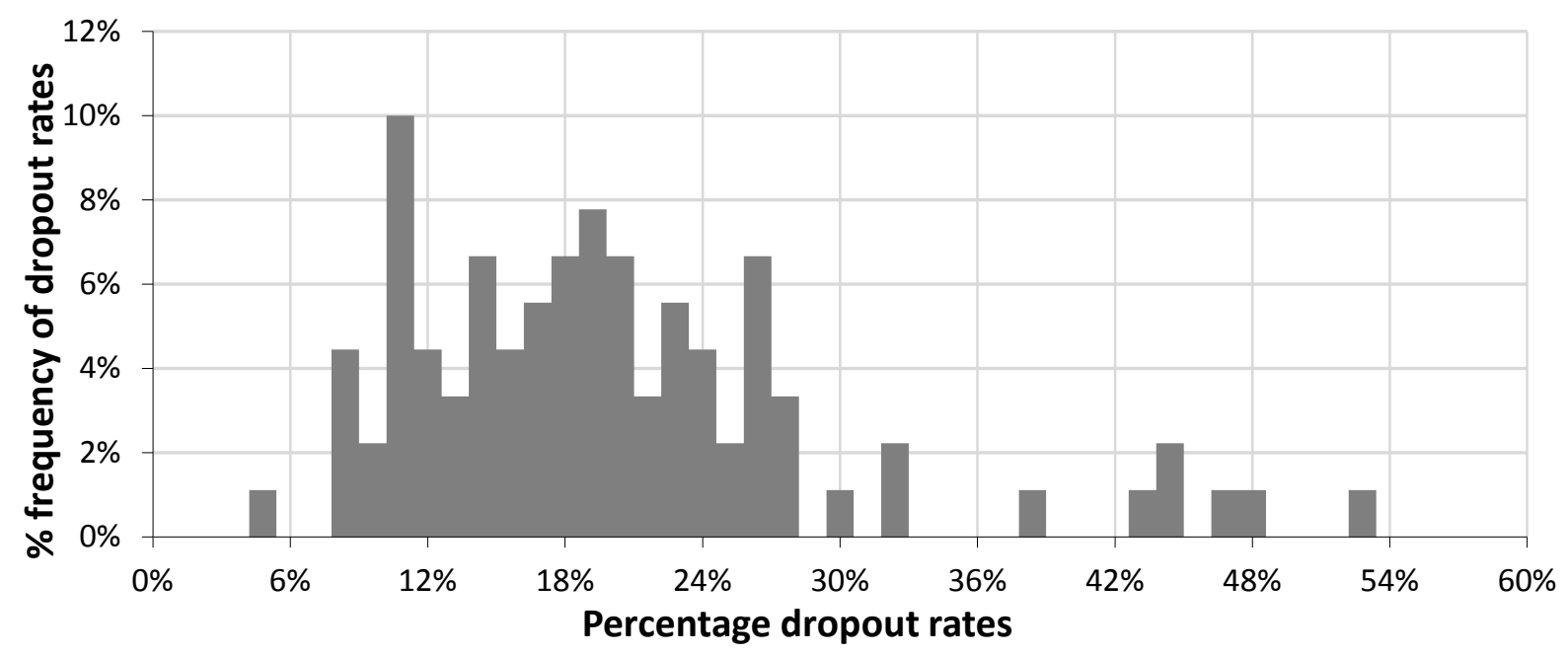

Figure 1: Empirical Distribution Of Dropout Rates For Master's Degrees For The Period 2008-2012 


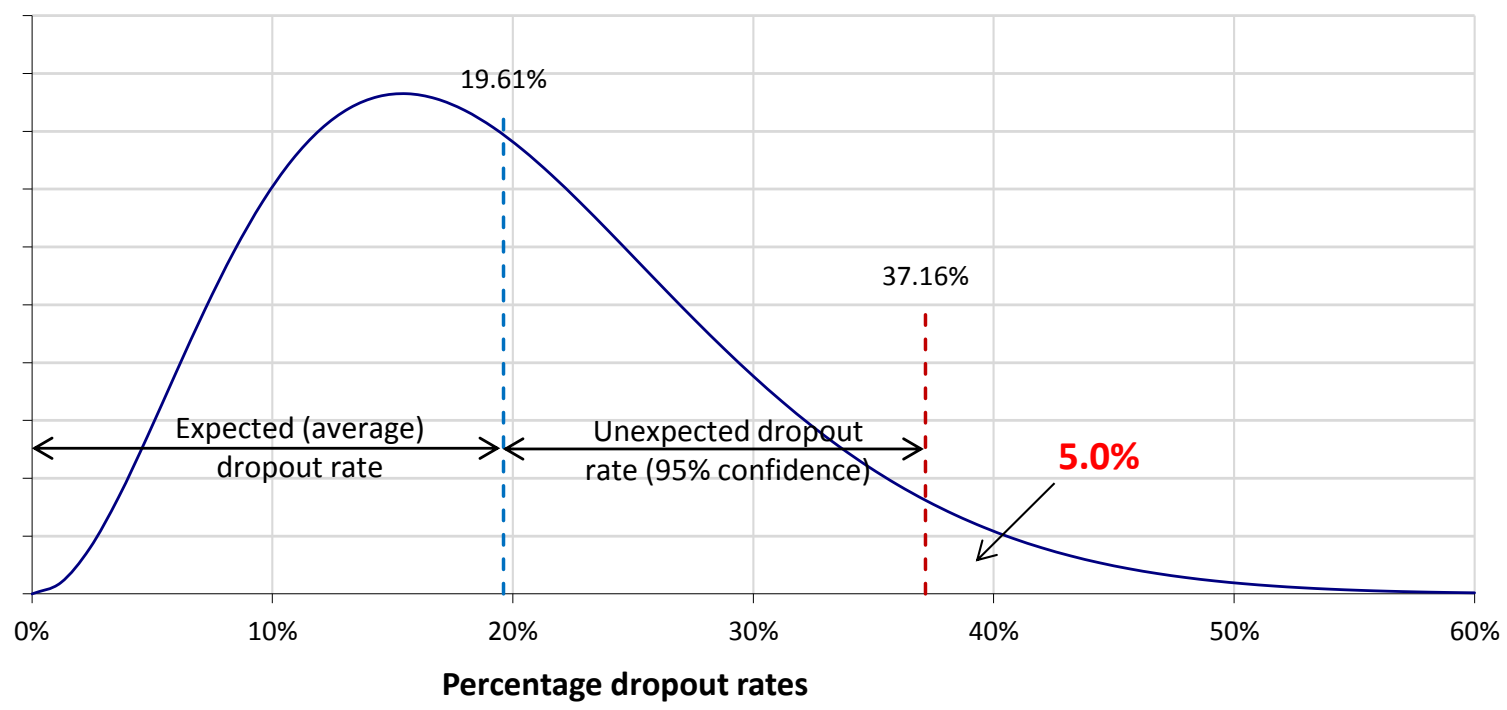

Figure 2: Beta-Fitted Distribution Of Master's Withdrawal Rates From 2008-2012 Showing Relevant Parameters

Indicated in Figure 2 is the $95 \%$ confidence point $(37.2 \%)$ below which the percentage dropout rate is expected $95 \%$ of the time. Viewed in a different way, more than $37.2 \%$ of students abandon their master's studies only $5 \%$ of the time

Figure 3 shows the histogram of empirical doctoral degree dropout rates for the same period; i.e., from 2008 to 2012.

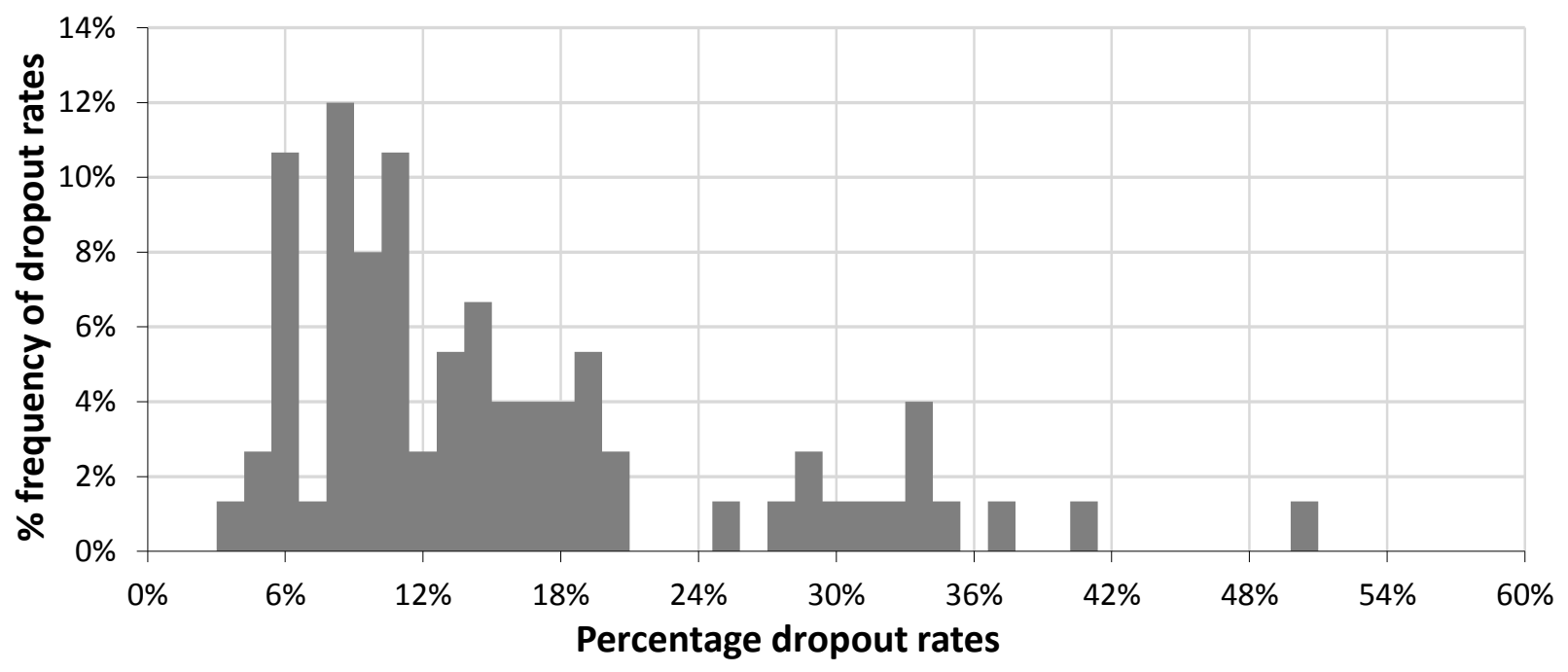

Figure 3: Empirical Distribution Of Dropout Rates For Doctoral Degrees From 2008-2012 
Applying Equations 1 through 3 to these data determines the probability density function for doctoral degree dropouts as plotted in Figure 4.

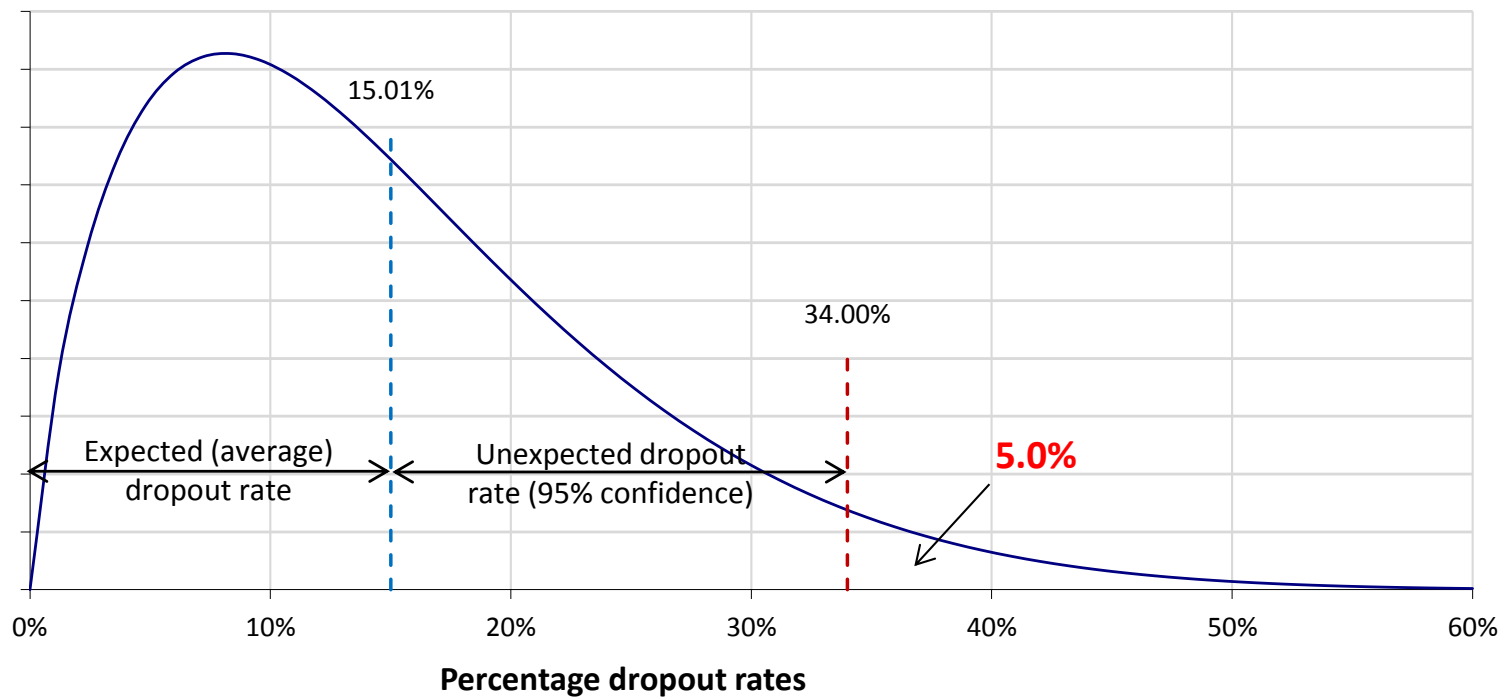

Figure 4: Beta-Fitted Distribution Of Doctoral Withdrawal Rates Showing Relevant Parameters

Indicated in Figure 4, again, is the 95\% confidence point (34.0\%) below which the percentage dropout rate is expected $95 \%$ of the time. Viewed in a different way, more than $34.0 \%$ of students abandon their doctoral studies only $5 \%$ of the time.

Using the different faculties within the university as cohorts, the data sample size may be increased and more accurate predictions may be made.

The second dataset is on the Programme Qualification Mix (PQM) for NWU for 2012. The PQM contains all information on existing qualifications offered at the institution, including the CESM category and number of credits of each module within the particular qualification. The data needed to be cleaned and sorted first since there are compulsory and selective modules. Student enrolments in selective modules have the potential to let students enrol for more than the maximum number of credits that are permitted for a particular curriculum for a given year. The assumption was made that students had to take compulsory modules first and can only enrol for selective modules up to the maximum amount of credits for that particular curriculum in the particular year of study. Otherwise, students could enrol endlessly and be subsidised beyond the maximum for any given qualification.

These data were used to construct the exact maximum income received from subsidy per student head if they complete their studies within the minimum time of the qualification. Potential losses based on the output grants from subsidy can be calculated accurately on curriculum level. The programme qualification and presentation of the curriculum can also be specified to account for all the possibilities in weighting factors defined by the ministerial statement for funding of higher education in South Africa. The data were then filtered to look only at postgraduate students. The reason for this decision was, as mentioned above, to look at research lost due to the student dropout rate.

For the purpose of the study, the number of years it takes to complete a qualification was not taken into account, nor was the potential loss from class fees.

\section{RESULTS}

From the construction of the model to determine the income from subsidy, the losses may also be determined. In theory, the potential loss in subsidy for a master's degree are the teaching output and research output 
grants, and since the construction of qualifications differs, the losses will differ between qualifications. For a doctoral degree, the potential loss in subsidy is the research output grant.

For master's degrees, the calculations are a bit more complicated as the curricula for master's degrees differ from each other. For this reason, the percentage of research master's degrees in 2012 was taken and the assumption was made that the percentages will stay the same for 2013. In 2012, 64.6\% of all master's degrees awarded at NWU were research master's degrees; therefore, $35.4 \%$ were taught units. Figure 5(a) shows the cumulative loss for different scenario levels for master's degrees. The expected number of master's degree dropouts is 567 students for NWU and the expected loss from dropouts is more than R46mn.

The scale for Figure 5(a) is the same as that used for Figure 6(a) for comparison.
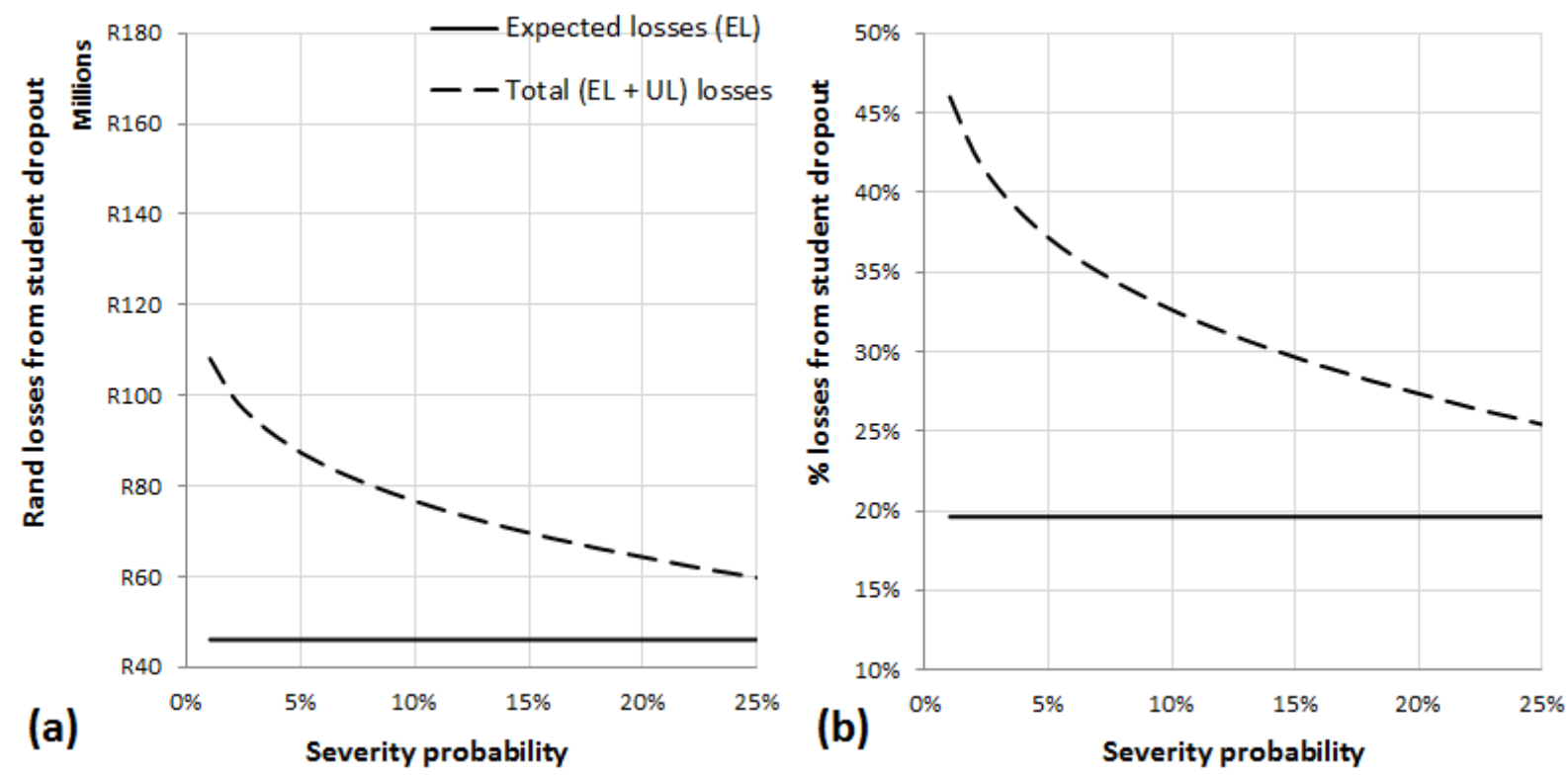

Figure 5: Expected And Unexpected Losses In Rand In (A) And Percentage Of Income In (B) For Master's Degrees

For master's degrees, the model was adjusted to calculate the predicted dropouts for every curriculum, based on the distributed dropouts for the faculty where this curriculum is delivered. The module combination for the particular curriculum provides for exact subsidy value calculations. From Figure 5(a), it can be deduced that for master's students, apart from the expected loss, there is, for example, a 5 in $100(5 \%)$ chance that the unexpected loss will be R41mn, a 1 in 100 (1\%) chance that the unexpected loss will be R62mn, etc. As with doctoral degrees, the relationship between the severity probability and the financial loss due to student dropout rate is not linear, but exponential. The expected and unexpected losses are plotted against the severity probability; i.e., the probability of the event occurring. In Figure 5(b), the percentage of student dropout rate for master's degrees is also plotted against the probability of the event occurring. There is, for example, a 5 in a $100(5 \%)$ chance that the total income from subsidy for master's degrees could be up to $37.1 \%$ less than the potential income, a 1 in $100(1 \%)$ chance that the total income from subsidy for master's degrees could be up to $46.0 \%$ less than the potential income, etc. for any given year, and the relationship is exponential rather than linear.

To calculate the potential loss from research grants for doctoral degrees is simpler than for master's degrees, since the latter have different combinations for research and teaching output. All doctoral degrees have three research output units in terms of subsidy. The potential loss is therefore the predicted number of student dropout rates multiplied by three multiplied by the amount per research output unit. If the assumption is made that the amount per unit remains the same as in 2012 (R115,000), the cumulative loss for different scenario levels is as shown in Figure 6(a). Figure 6(b) shows the percentage reduction in potential income from student dropout rates for doctoral degrees. The expected number of doctoral degree dropouts is 172 students for NWU and the expected loss from dropouts is over R59mn. 
From Figure 6(a), it can be deduced that for doctoral students, apart from the expected loss, there is, for example, a 5 in $100(5 \%)$ chance that the unexpected loss will be R75mn, a 1 in a $100(1 \%)$ chance that the unexpected loss will be R116mn, etc. The expected and unexpected losses are plotted against the severity probability; i.e., the probability of the event occurring. In Figure 6(b), the percentage of reduction in potential income from the student dropout rate for doctoral degrees is also plotted against the probability of the event occurring. There is, for example, a 5 in $100(5 \%)$ chance that the total income from subsidy for doctoral degrees could be up to $34.0 \%$ less than the potential income, a 1 in $100(1 \%)$ chance that the total income from subsidy for doctoral degrees could be up to $44.5 \%$ less than the potential income, etc. for any given year, and the relationship is exponential rather than linear.
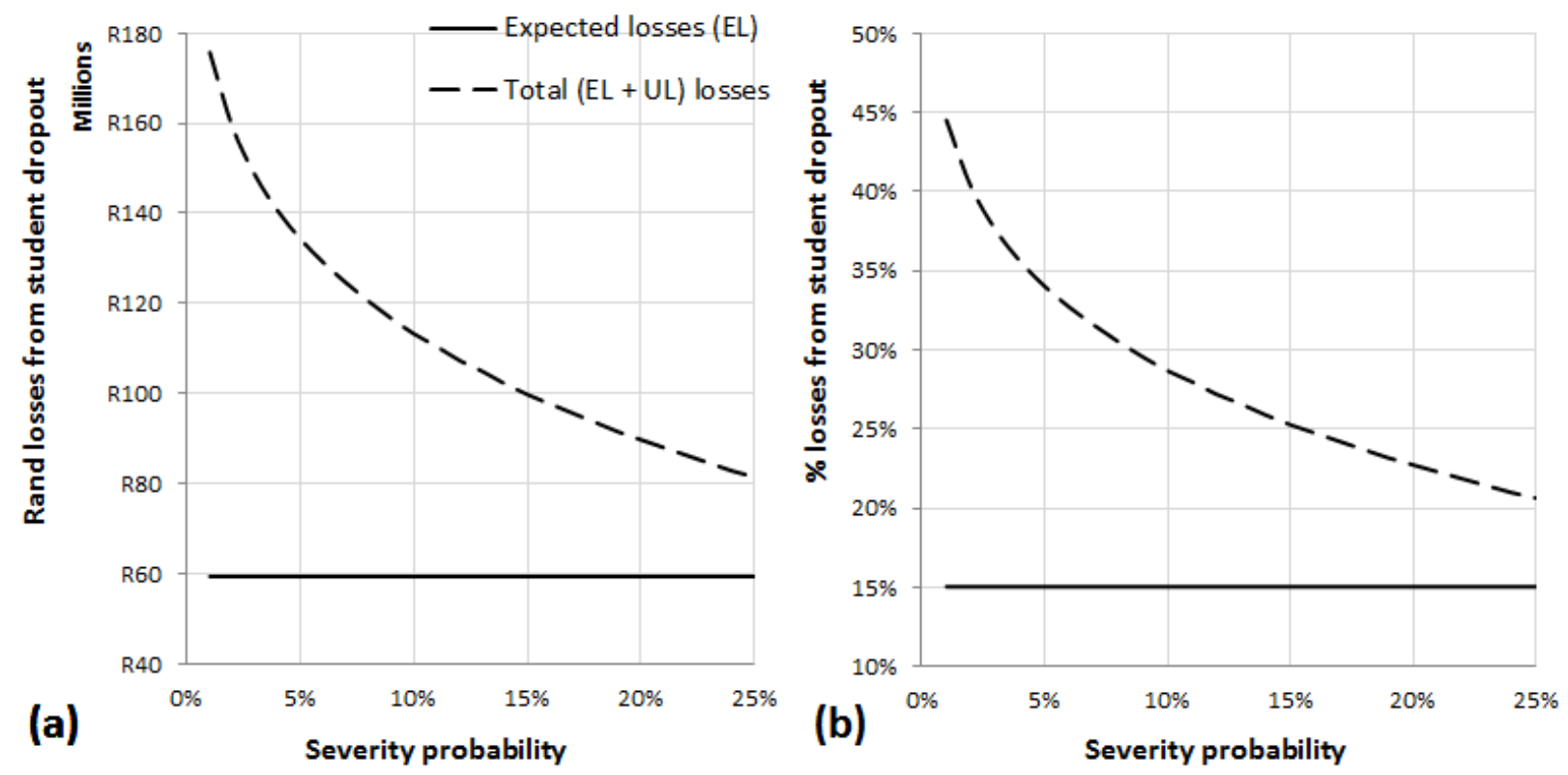

Figure 6: Expected And Unexpected Losses In Rand In (A) And In Percentage Of Income In (B) For Doctoral Degrees

The optimum scenario would be to fit the beta distribution (or whichever model fits best) for every curriculum to predict the dropouts for each curriculum, but some curricula have very few student enrolments. These data would skew the results and possible future research would be to look at dropouts for similar curricula on a national scale. The same goes for using only data for five years; the data points may be insufficient, although the distribution fits the data very well. Again, national research might provide clearer results.

The data indicate that the percentage of master's degree dropouts is decreasing over the years. In 2009, $17.5 \%$ master's students left NWU without completing their studies and the percentage decreased to $16.4 \%$ in 2012 , with a low of $15.8 \%$ in 2011 . Figure 7 shows the dropouts for master's degrees.

Doctoral degree dropouts, on the other hand, are increasing; in 2009, 12.4\% doctoral students left NWU without completing their studies and the percentage increased to $13.0 \%$ in 2012, with a low of $11.4 \%$ in 2011. Figure 8 shows the dropouts for doctoral degrees. 


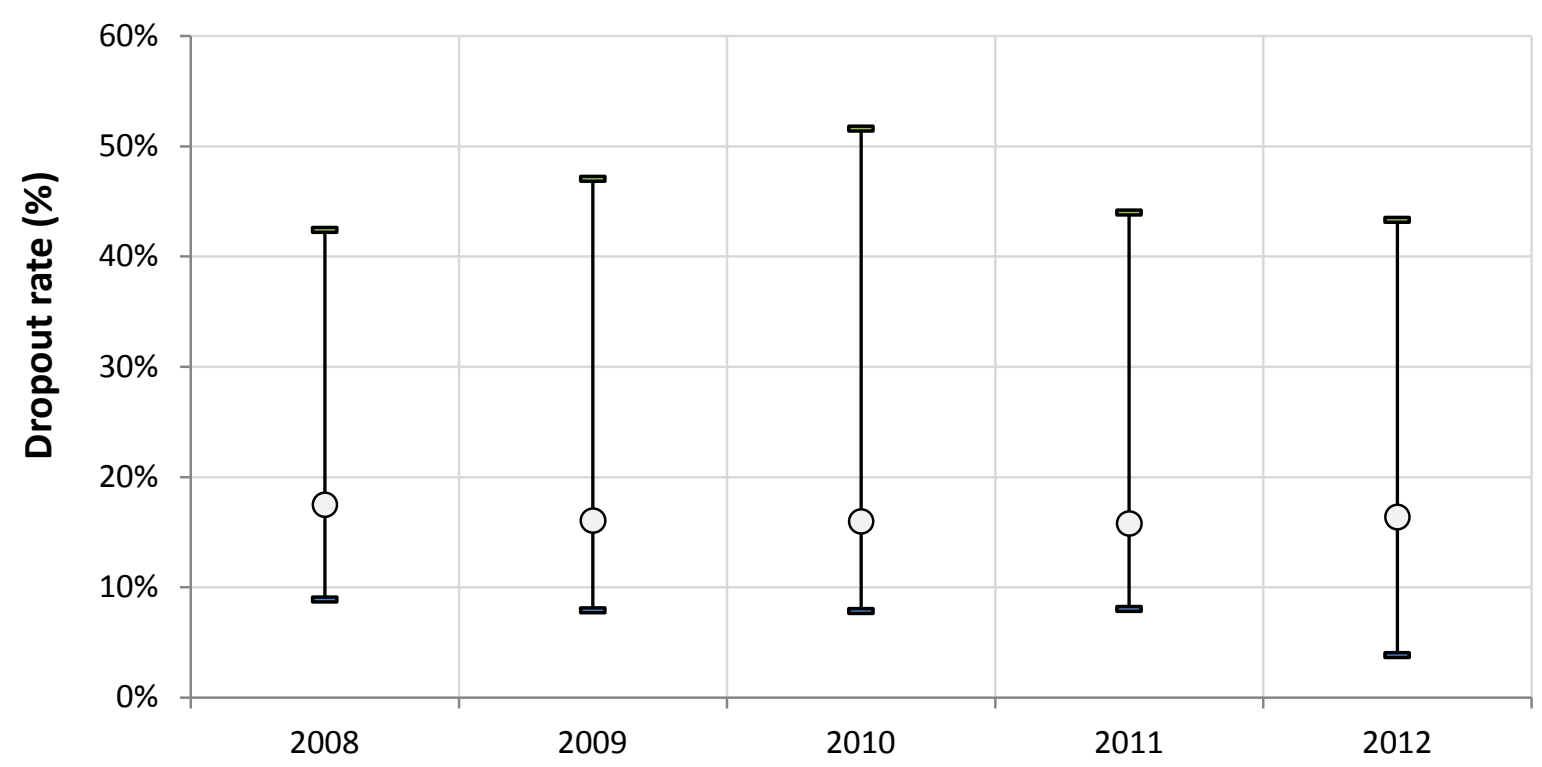

Figure 7: Dropout Percentages For Master's Degrees

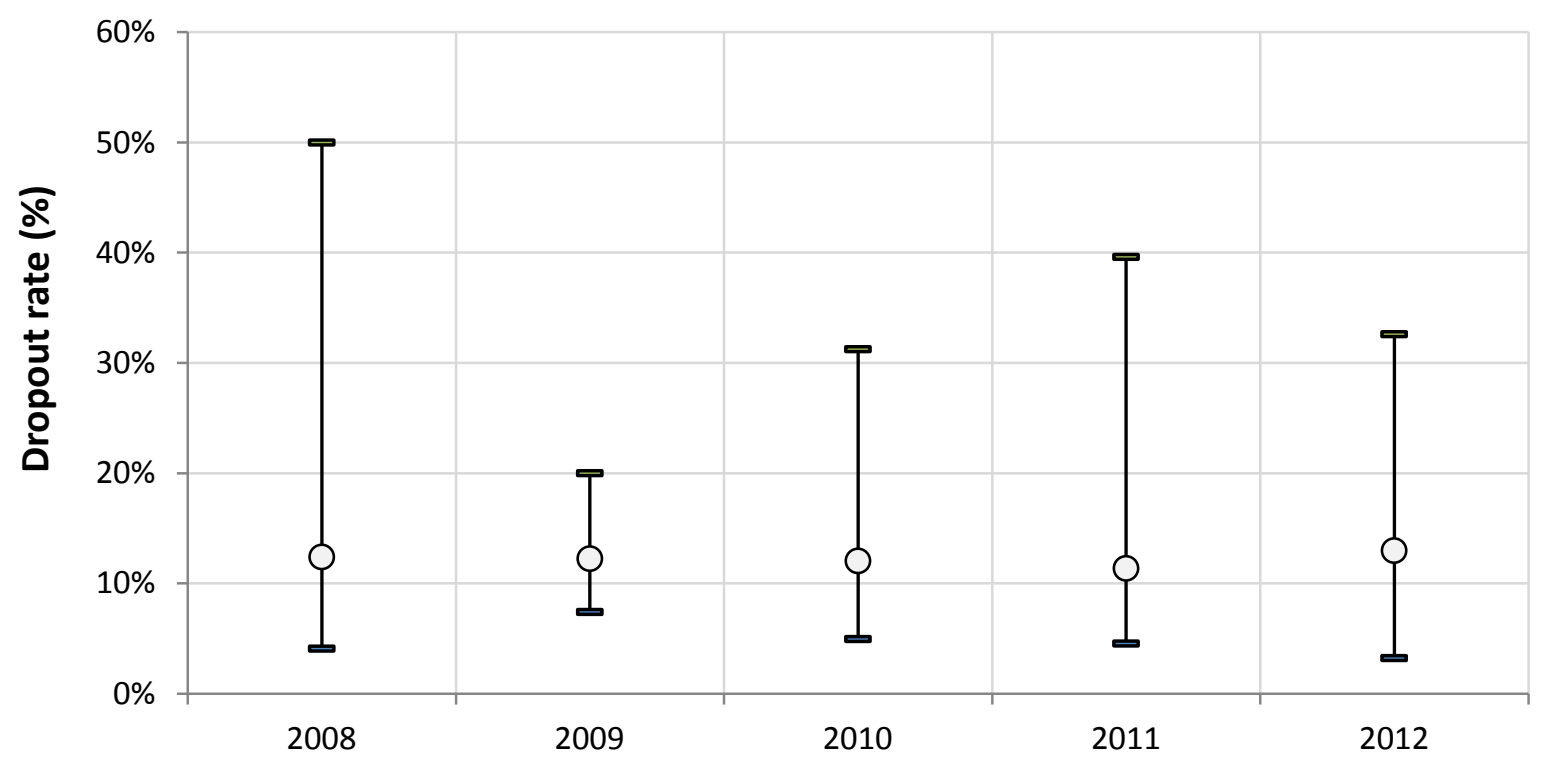

Figure 8: Dropout Percentages For Doctoral Degrees

In 2011, both master's and doctoral degree dropout were at their lowest. Percentages also differ between faculties; for example, in 2012, the minimum dropout percentage for master's degrees was only $3.8 \%$, while the maximum was as high as $43.3 \%$. For 2012 , doctoral degree dropout percentages ranged from a minimum of $3.2 \%$ to a maximum of $32.6 \%$. The maximum dropout percentage for doctoral degrees was 50.0\% in 2008. Figure 9 shows the cumulative beta distribution dropout rate probabilities for the two postgraduate degrees. 




Figure 9: Cumulative Beta Distribution Dropout Rate Probabilities For Both Masters And Doctoral Postgraduates

To interpret Figure 9, note that for master's degrees there is a 50\% chance the dropout rate will be $18.4 \%$ or less and for PhDs, there is a $50 \%$ chance the dropout rate will be $13.1 \%$ or less.

\section{CONCLUSION}

Letseke and Maile (2008) raised concerns about the low graduation rate of only 15\% in South Africa, especially since the country has a shortage of quality graduates in the labour market. The results of this case study show large amounts of losses in subsidy and also in human capital for only one university in South Africa. The purpose of this study was to show financial losses from the student dropout rate and the results should make management more aware of the consequences of the student dropout rate - for example, Figures 5(b) and 6(b) with the reduction in potential income for master's and doctoral degrees. Most universities do not take the student dropout rate as seriously as they should and, according to Koen (2007), statistics such as the ones in this study would force institutions to look more closely at student retention.

When students drop out, the financial loss is the teaching input unit and research output unit (if any) part of government subsidy. This study did not take the effect on class fees into consideration, but losses are also expected in this area. In an email conversation on 15 October 2013, E. de Beer stated that class fees for a particular curriculum are based on the national inflation (CPI), internal inflation and market-related prices; no dropout is taken into account. In theory, class fees for an entire year are lost from students who leave the university before completing their studies. It would be wise to consider the student dropout rate in determining class fees in order to price in the unexpected losses and be insured in some way.

To deal with expected losses from the student dropout rate, especially postgraduates, South African universities should pay more attention to student retention. More research is needed on the unexpected loss to see whether national trends are influencing a rise or fall in the number of students who do not complete their studies. Koen (2007) mentioned the fact that universities that are financially viable tend not to attend to student retention, but those that have financial difficulties look at the student dropout rate at the postgraduate level as a first concern.

A suggestion is that the student dropout rate should be taken into consideration with the review of the funding framework for university funding. Universities with low dropout rates could be rewarded or those with high dropout rates could be penalised. 
Much more research is needed on the student dropout rate and retention in South Africa. University funding from government forms a large part of income for most universities and is a considerable investment into education from public funding (Ministry of Higher Education and Training, 2012:20). Country-wide shortages in scarce skills should be one of the most important areas where universities utilise these funds. Student dropout rate plays a negative role in producing those who can contribute to the national shortage and should be addressed with the utmost urgency.

This case study only focused on postgraduate students. Students need to go through undergraduate studies first to become a postgraduate student. Letseka et al. (2009) raised concern about the fact that $50 \%$ of all undergraduate students will never make it to graduation. Research on the student dropout rate and retention in undergraduate studies in South Africa is an urgent suggestion. If only 50\% of students graduate from their undergraduate studies and not all of them enrol for postgraduate studies, many potential skills are going to waste. Retaining undergraduates would be an efficient way of getting a larger pool of potential postgraduate students that can contribute to the shortage in research in scarce skills in South Africa.

\section{AUTHOR INFORMATION}

Anton Styger began his career in 2008 as a researcher (and later, senior researcher) in the Department of Marketing and Communications at the North-West University's Potchefstroom Campus. In 2010, he moved to the office of the Vice-Rector for Research and Planning in the position of Manager for Planning and Management Information for the Potchefstroom Campus. He authored this paper as part of his Masters degree in Risk Management in 2013. Anton is currently the Manager for Planning and Management Information at North-West University, Potchefstroom, South Africa. E-mail: anton.styger@nwu.ac.za. (Corresponding author)

Gary van Vuuren, Ph.D., Extraordinary professor at the School of Economics, North-West University, Potchefstroom Campus, South Africa, began his career with a Masters in astrophysics and Ph.D. in nuclear physics. After a short time at Goldman Sachs in London, he obtained his Masters in market risk and Ph.D. in credit risk and then worked as a risk manager for large South African retail banks and asset managers. He then moved to London where he was employed as a risk manager for several retail and investment banks before settling on risk assessment and regulatory compliance in financial institutions for Fitch Ratings where he remains employed. He is an accredited GARP Financial Risk Manager. E-mail: vvgary@ hotmail.com.

André Heymans, Ph.D., Program leader in Risk Management at the School of Economics, North-West University, Potchefstroom, South Africa. After completing his Ph.D. in finance in 2007, André moved to London where he was employed by BNY MELLON until the middle of 2008. He then moved to South Africa to fill the position of Head of Research and Development in the trading room at an agricultural trading firm (Free State Maize). André moved back to academia in April 2009 where he currently holds the position of Program Head of Risk Management. Email: andre.heymans@nwu.ac.za.

\section{REFERENCES}

1. ASSAF [Academy of Science of South Africa]. (2010). The PhD Study. Consensus Report. Retrieved 10 Oct., 2013, from http://www.assaf.co.za/wp-content/uploads/2010/10/40696-Boldesign-PHD-smalloptimised.pdf.

2. Crest [Centre for Research on Science and Technology]. (2009). Higher Education Monitor: Postgraduate Studies in South Africa - A Statistical Profile. Retrieved 10 Oct., 2013, from http://www.che.ac.za/sites/default/files/publications/CHE_MonitorProjectV7.pdf.

3. De Villiers, A. P. (2009). The cost of fiscal subsidies to higher education students in South Africa: A comparison between 2000 and 2006. Retrieved 24 Feb., 2012, from http://www.ekon.sun.ac.za/wpapers/2009/wp132009/wp-13-2009.pdf.

4. Department of Higher Education and Training. (2013). Statistics on Post-School Education and Training in South Africa: 2011. Retrieved 28 Oct., 2013, from http://www.saqa.org.za/docs/papers/stats2011.pdf.

5. Department: Science and Technology. (2007). The Ten-Year Plan for Science and Technology. Retrieved 28 Oct., 2013, from http://www.info.gov.za/view/DownloadFileAction?id=94066. 
6. Iputo, J. E., \& Kwizera, E. (2005). Problem-based learning improves the academic performance of medical students in South Africa. Medical Education, 39(4):388-393.

7. Koen, C. (2007). Postgraduate student retention and success: A South African case study. Retrieved from 14 Oct., 2013, http://www.hsrcpress.ac.za/product.php?productid=2205\&cat=1\&page=1\#sthash.051OpuhU.dpuf.

8. Kritzinger, E., \& Loock, M. (2012). A critical investigation into the current shortage of information technology postgraduates produced by Unisa. Retrieved from 01 Oct., 2013

http://uir.unisa.ac.za/bitstream/handle/10500/8500/Final_Kritzinger\%20E\%20Loock\%20M\%20ODL-0312012.pdf?sequence $=1$.

9. Lau, L. K. (2003). Institutional factors affecting student retention. Retrieved from 14 Oct., 2013, http://www.uccs.edu/Documents/retention/2003\%20Institutional\%20Factors\%20Affecting $\% 20$ Student $\% 20$ Retention.pdf.

10. Letseka, M., \& Maile, S. (2008). High university drop-out rates: a threat to South Africa's future. Retrieved from 01 Oct., 2013, http://www.hsrc.ac.za/uploads/pageContent/1088/Dropout\%20rates.pdf.

11. Letseka, M., Cosser, M., Breier, M., \& Visser, M. (2010). Student Retention and Graduate Destination: Higher Education and Labour Market Access and Success. Retrieved from 10 Oct., 2013, http://www.hsrcpress.ac.za/product.php?productid=2272\&freedownload=1.

12. Lubben, F., Davidowitz, B., Buffler, A., Allie, S., \& Scott, I. (2009). Factors influencing access students' persistence in an undergraduate science programme: A South African case study. International Journal of Educational Development, 30(4):351-358.

13. Ministry of Higher Education and Training. (2012). Ministerial statement on university funding: 2013/14 and 2014/15.

14. North-West University. (2012). Potchefstroom Campus Plan 2013-2015.

15. Pretorius, A. M., Prinsloo, P., \& Uys, M. D. (2010). The impact of raising students' risk awareness in Introductory Microeconomics. Progressio, 32(1):131-154. 
NOTES 